\title{
APLICAÇÃO DE MODELAGEM GEOESTATÍSTICA POR KRIGAGEM PARA MAPEAMENTO DO RELEVO EXPOSTO E DO PALEO-RELEVO SOTOPOSTO À BACIA SEDIMENTAR DE CURITIBA(PR)
}

\author{
APPLICATION OF GEOSTATISTICAL MODELING FOR KRIGING \\ FOR THE MAPPING OF THE EXPOSED RELIEF AND THE PALEO- \\ RELIEF UNDER THE SEDIMENTARY BASIN OF CURITIBA, \\ PARANÁ STATE (BRAZIL)
}

\begin{abstract}
Edison Archela
Universidade Estadual de Londrina (UEL), Centro de Ciências Exatas, Departamento de Geociências, Rodovia Celso Garcia Cid, PR 445, Km 380, Campus Universitário, Cx. Postal 6001, CEP 86051-980, Londrina/PR.

E-mail: arrchela@uel.br

Silvano Cesar da Costa

Universidade Estadual de Londrina (UEL), Centro de Ciências Exatas, Departamento de Estatística, Rodovia Celso Garcia Cid, PR 445, Km 380, Campus Universitário, Cx. Postal 6001, CEP 86051-980, Londrina/PR.

E-mail: silvano@uel.br

Jaqueline Aparecida Raminelli

Universidade Estadual de Londrina (UEL), Centro de Ciências Exatas, Departamento de Estatística, Rodovia Celso Garcia Cid, PR 445, Km 380, Campus Universitário, Cx. Postal 6001, CEP 86051-980, Londrina/PR.

E-mail: raminelli@uel.br
\end{abstract}

Informações sobre o Artigo

Data de Recebimento:

$14 / 03 / 2013$

Data de Aprovação: 04/07/2013

Palavras-chave:

Bacia Sedimentar de Curitiba; paleo-relevo; formação Guabirotuba.

Keywords:

Sedimentary Basin of Curitiba; paleo-relief; Guabirotuba formation.

\section{Resumo}

Este trabalho tem por objetivo apresentar o produto cartográfico em 2D e 3D dos relevos, atual e pretérito, na área de abrangência das exposições dos sedimentos pertencentes à Bacia de Curitiba. Paralelamente foi construído o mapa do relevo atual seguindo a mesma metodologia empregada na obtenção do mapa do paleo-relevo; sendo que esse procedimento contribuiu para se estabelecer elos comparativos entre os dois produtos cartográficos, permitindo conclusões e interpretações acerca das características dos relevos e da tendência geológico-estrutural da superfície enterrada; bem como, testar a confiabilidade do modelo matemático, uma vez que o relevo atual é bem conhecido. Para este estudo, foram utilizados dados provenientes da perfuração de poços tubulares profundos para explotação de água subterrânea na Região Metropolitana de Curitiba. Os dados foram trabalhados em software computacional utilizando-se do método de interpolação da "krigagem". Os resultados mostraram que: 1) o mapa do relevo atual, obtido por aproximação a partir de dados pontuais aleatórios, mostrou-se fidedigno quando comparado com cartas topográficas obtidas por topografia convencional; 2) as feições geomorfológicas do paleo-relevo enterrado apresentam características muito semelhantes daquelas observadas no relevo atual; 3) o "trend" estrutural do embasamento sotoposto aos sedimentos, com evidentes linhas de estruturação de blocos na 
direção NNE-SSW, reforçam a tese de uma gênese tectônica para a Bacia de Curitiba, associando-a as demais bacias tafrogênicas que compõem o "Rift Continental do Sudeste do Brasil"; e 4) As principais drenagens pretéritas assemelham-se muito às atuais, não só nas distribuições geográficas, mas principalmente na função de agentes de transporte e retrabalhamento dos sedimentos aluviais, ocupando os depocentros alinhados do paleo-relevo.

\begin{abstract}
This paper aims to present the cartographic product in 2D and 3D reliefs, current and past, in the catchment area of exposures of sediments belonging to Curitiba Basin. Parallel map was constructed of relief today following the same methodology used to obtain the map of paleo-relief, and this procedure helped to establish links between the two comparative cartographic products, allowing conclusions and interpretations about the characteristics of the reliefs and the trend geological and structural buried surface, as well as to test the reliability of the mathematical model, since the current emphasis is well known. For this study, we used data from the drilling of deep wells for groundwater exploitation in the Metropolitan Region of Curitiba. The data were worked in computer software using the interpolation method of "kriging". The results showed that: 1) the current relief map, obtained by approximation from random data points, proved to be accurate when compared with topographic maps obtained by conventional topography, 2) the geomorphological features of the buried paleo-relief show characteristics very similar to those observed in the present relief, 3) the trend structural of the basement underneath of the sediments, with clear lines of structuring block in the NNE-SSW direction, reinforce the hypothesis of a tectonic genesis for the Curitiba Basin, associating it with other taphrogenic basins that comprise the "Continental Rift of Southeastern Brazil", and 4) the main drainages preterit closely resemble the present, not only in geographic distributions, but mainly in the role of carriers and reworking of alluvial sediments, occupying depocenters aligned the paleo-relief.
\end{abstract}

\section{Introdução}

Paleo-superfícies enterradas, sotopostas a pacotes sedimentares, são objetos de investigação em trabalhos de mapeamento geológico. A identificação do relevo do embasamento de uma bacia sedimentar permite a visualização de depocentros sedimentares; contribui para a interpretação de sua história tectono-sedimentar; permite a elaboração de isópacas com ideal visualização espacial da disposição volumétrica nos diferentes estratos sedimentares; bem como, auxilia na interpretação da paleogeografia. Sua obtenção, via de regra, é possível por aproximação, pela construção matemática de superfícies contínuas obtidas a partir de informações pontuais descontínuas, quase sempre aleatórias, fazendo-se uso do tratamento geoestatístico destas. Este trabalho tem por objetivo apresentar o produto cartográfico em 2D e 3D dos relevos atual e pretérito na área de abrangência das exposições dos sedimentos pertencentes à Bacia de Curitiba.

\section{Localização da área estudada}

A área de exposição dos sedimentos da Bacia de Curitiba ocorre na porção centro-sul da Região Metropolitana de Curitiba (figura 1). Os sedimentos afloram em quase a totalidade da extensão ocupada pelos municípios de Curitiba e Pinhais; bem como, boa parte da área ocupada pelos municípios de Araucária, Fazenda Rio Grande, São José dos Pinhais, Piraquara, Quatro Barras, Campina Grande do Sul e Colombo; além de pequenas e isoladas ocorrências nos municípios de Mandirituba, Almirante Tamandaré e Campo
Magro; o que totaliza, aproximadamente, $3.000 \mathrm{~km}^{2}$ de exposições com contornos irregulares (figura 2).

A localização geográfica dessa região pesquisada enquadra-se numa área retangular compreendida entre as longitudes $49^{\circ} 00^{\prime}$ e $49^{\circ} 30^{\prime}$ a oeste de Greenwich, e latitudes $25^{\circ} 15^{\prime}$ e $25^{\circ} 45^{\prime}$ a sul do Equador; ou mais precisamente entre 655 e 705 quilômetros E e 7155 e 7200 quilômetros N na Unidade Transversa de Mercator (UTM).

\section{Geomorfologia Regional}

A visão geomorfológica clássica descreve, resumidamente, o Primeiro Planalto como sendo uma zona de superfícies aplainadas entre a Serra do Mar e a Escarpa Devoniana. A atual superfície deste compartimento seria o resultado de um plano de erosão recente atuante sobre uma pretérita paisagem montanhosa.

Ab'Saber e Bigarella (1961) reconheceram quatro superfícies erosivas de aplainamento para a região em foco, sendo o Paleoplano Pré-Devoniano a superfície mais antiga, dedutível a partir do prolongamento hipotético da superfície do embasamento cristalino que jaz sob os depósitos da Formação Furnas. Esta superfície foi denominada, pelos autores acima referidos, de "superfície fóssil", em razão de a mesma poder ser detectada diretamente sob as camadas do estrato sedimentar, servindo durante boa parte do Eon Fanerozóico como assoalho oceânico. O segundo aplainamento, denominado por Superfície do Purunã, seria um plano erosivo dedutível a partir do prolongamento hipotético de uma superfície ligando os topos da Serra da Bocaina e da Serra do Purunã, resultante 
dos sucessivos aplainamentos cretácicos-eocênicos. A Superfície do Alto Iguaçu, por sua vez, foi interpretada como um plano de erosão resultante do esculpimento do Primeiro Planalto Paranaense ao nível do pré-Guabirotuba, através das drenagens que compunham o Alto Iguaçu. Finalmente, a quarta superfície erosiva de aplainamento, denominada por Superfície de Curitiba, foi identificada como sendo o plano atual do sítio urbano de Curitiba, onde jazem os sedimentos homônimos de gênese cenozóica.

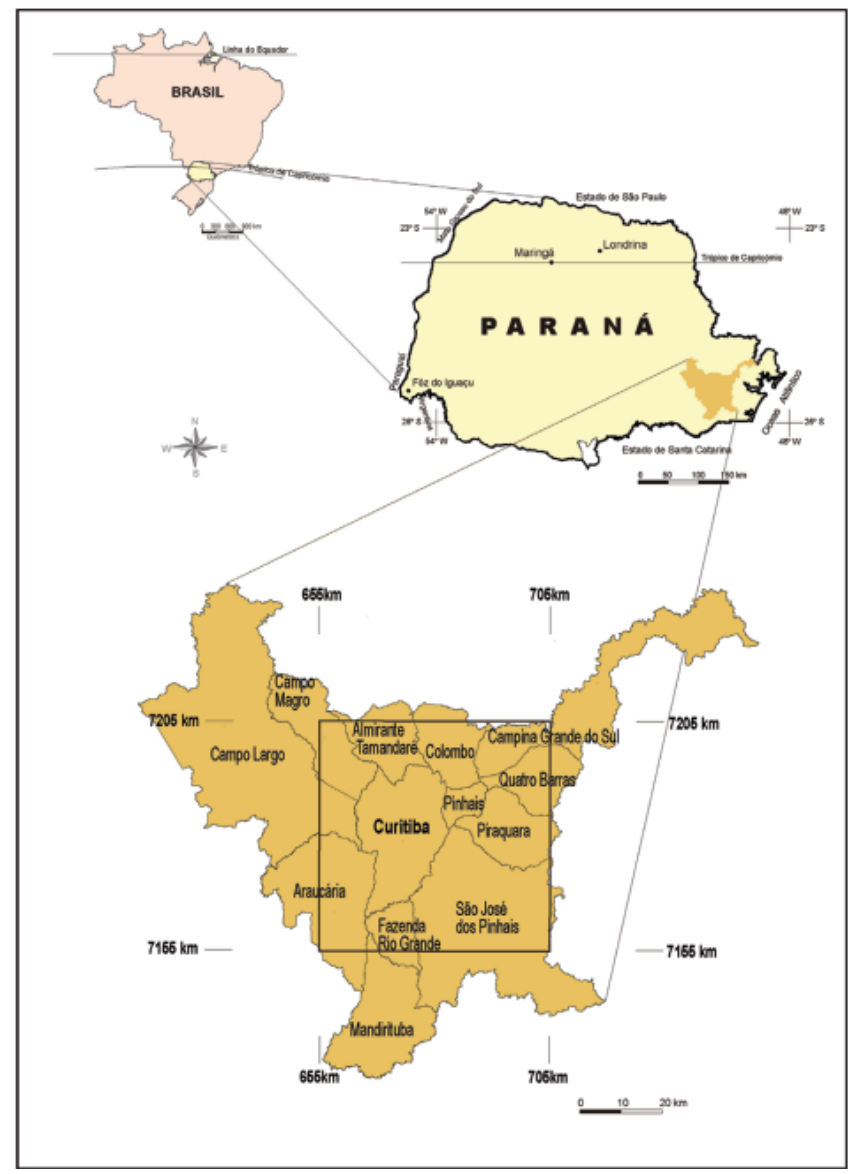

Figura 1-Localização da área de estudo.

Uma visão do Primeiro Planalto Paranaense sob o prisma da geologia estrutural poderia nos fornecer, num primeiro momento, a interpretação de um falso graben para o compartimento como um todo; porém, uma análise mais profunda à luz da dinâmica interna, como também da susceptibilidade dos materiais frente ao intemperismo, nos remete a uma interpretação mais elaborada sobre os fatores que contribuíram para a atual conformação fisiográfica regional; ou seja, o processo erosivo atuante na região pode ter sofrido atenuações ou aumentos de intensidade, frutos das modificações climáticas reinantes ao longo de milhões de anos. Porém, esta ação se fez regionalmente e não por setores. Neste raciocínio, justifica-se o relevo positivo ostentado pela Cuesta do Purunã, em relação ao planalto, em razão de sua constituição mineral, predominantemente quartzosa, ser muito mais resistente ao intemperismo químico, dificultando seu processo erosivo. Por outro lado, a existência do relevo positivo da Serra do Mar não pode ser explicada da mesma forma, pois sua constituição litológica não difere, em essência, daquela presente nos terrenos do Primeiro Planalto. Tal fato vem reforçar a necessidade de um rejuvenescimento do relevo, se não constante, ao menos episódico, o que compactua com os movimentos verticais ascendentes apregoados para a Serra do Mar (SALVI et al., 2002).

A área estudada situa-se na porção centro-sul do Primeiro Planalto Paranaense, cuja fisiografia difere daquela verificada no restante do planalto. As altitudes médias estão próximas de 905 metros, predominando sobre os sedimentos da Bacia de Curitiba. As altitudes mínimas ocorrem na porção sul da área da bacia, e as altitudes máximas ocorrem no entorno, em direção à Serra do Mar e à Serra do Purunã, onde atingem até 1009 metros. O relevo, entalhado sobre as rochas cristalinas do Pré-Cambriano, apresenta-se suavemente arredondado com vales em forma de "V", bem abertos. Nas áreas cobertas por sedimentos da Bacia de Curitiba, a topografia é pouco acidentada, apresentando poucas elevações, com vales bem abertos, onde as planícies aluviais são comuns, existindo inclusive, planícies de soleira. As intrusões de diabásios e andesitos formam linhas de cristas secundárias, orientadas dominantemente na direção NW-SE. Ocasionalmente, quando os diabásios cortam rochas muito homogêneas, neles são entalhados vales.

\section{Geomorfologia local}

Em termos geomorfológicos, os domínios da Bacia Sedimentar de Curitiba são muito maiores, desdobrando-se até o limite a leste, representado pela escarpa da Serra do Mar, a oeste pela escarpa Serrinha - São Luiz do Purunã, ao norte pelos rios Ribeira do Iguape, Açungui, São Miguel, Uberaba, Piedade e Serra da Antagorda, e ao sul pelos rios da Várzea e Capivari.

As altitudes mínimas ocorrem na porção sul da área da Bacia, cuja média é de 905 metros. As altitudes máximas ocorrem no entorno, em direção à Serra do Mar e à Serra do Purunã, onde atingem os 1009 metros. O relevo, entalhado sobre as rochas cristalinas do Pré-Cambriano, apresenta-se suavemente arredondado com vales em forma de "V", bem abertos. Nas áreas cobertas por sedimentos da Bacia de Curitiba a topografia é pouco acidentada, apresentando poucas elevações com vales bem abertos onde as planícies aluviais são comuns, existindo, inclusive, planícies de soleira. 


\section{Geologia local}

Geologicamente, a área estudada compreende terrenos com litologias e idades bem distintas, ou seja: predominância de metamorfitos pré-cambrianos - que constituem o embasamento cristalino de toda a área; e os sedimentos inconsolidados, com idades, provavelmente, miocênicas a pleistocênicas, constituindo os domínios da Bacia Sedimentar de Curitiba (figura 2).

Os terrenos pré-cambrianos representam cerca de $20 \%$ da litologia aflorante e $100 \%$ da totalidade da área, se considerado também o substrato rochoso formador do embasamento da Bacia Sedimentar de Curitiba. Desta forma podemos considerar o Complexo Pré-Setuva que corresponde ao Complexo Migmatítico de Battola Jr. (1978, apud Almeida \& Hasui, 1984) como a unidade litoestratigráfica dominante na área em foco; a qual é composta preferencialmente de migmatitos estromáticos com paleossoma de biotita-hornblenda gnaisse, mica-quartzo xistos, ultrabasitos, metabasitos e anfibolitos, que se distinguem dos migmatitos oftalmíticos e embrechíticos com paleossoma de biotita gnaisse, biotita-hornblenda gnaisse e hornblenda gnaisse, com quartzitos locais.

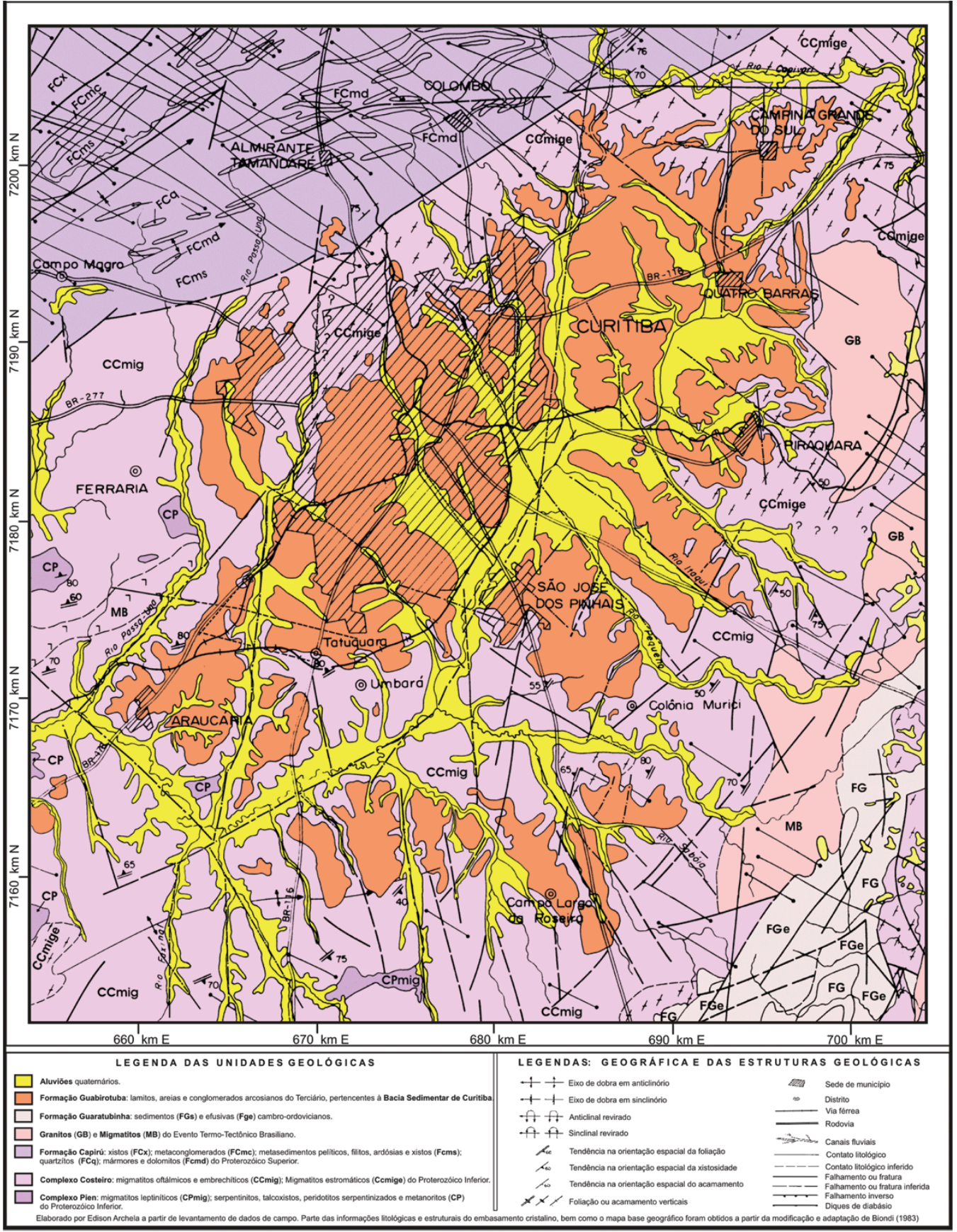

Figura 2 - Mapa Geológico da Bacia Sedimentar de Curitiba-PR. Fonte: Archela (2004). 
Do ponto de vista estrutural, o Complexo Migmatítico faz parte de um contexto regional mais amplo onde a tectônica transcorrente constitui uma das feições mais espetaculares. Regionalmente, os deslocamentos horizontais e desnivelamentos de blocos, introduzidos por essas falhas, geraram compartimentações proeminentes. Tidas como tardibrasilianas, as falhas não se distribuem de modo uniforme, mas compõem feixes de descontinuidades subparalelos a oblíquos, entrelaçantes ou não. Além destas, inúmeras outras de caráter normal existem, porém, de rejeitos e portes reduzidos em comparação com as transcorrentes.

Regionalmente, a Bacia Sedimentar de Curitiba faz parte do contexto das bacias tafrogênicas que compõem o "Rift Continental do Sudeste do Brasil" de Riccomini (1989). A concordância com uma gênese tectônica sincrônica, ou ao menos tardia, porém partícipe do mesmo contexto de sedimentação das bacias de São Paulo (SP), Taubaté (SP), Volta Redonda (RJ), Resende (RJ) e Itaboraí (RJ) é unânime, conforme Archela (1989, 1990), Salvador (1994), Salamuni (1998), Riccomini et al. (1996), Riccomini et al. (2004), Archela (2004, 2006), Salamuni et al. (2003), Archela \& Coimbra (2006), Archela \& Yamamoto (2007, 2008a, 2008b, 2008c)

\section{Materiais e Métodos}

Os dados pontuais sobre a topografia atual e a topografia do embasamento cristalino sotoposto aos sedimentos da Bacia de Curitiba foram obtidos a partir da análise de planilhas de descrição litológica e teste de vazão contida nos relatórios técnicos de perfurações de 276 poços tubulares profundos para explotação de água subterrânea, perfurados pela extinta Companhia T. Janér. Atualmente, esses relatórios integram o "Cadastro Geral de Poços do Estado do Paraná", cujo acervo encontra-se na Superintendência do Desenvolvimento dos Recursos Hídricos e Saneamento Ambiental (SUDERHSA), gentilmente cedidos para nossa pesquisa.

Vale ressaltar que os poços não estavam georreferenciados e não possuíam informações da localização cartográfica; contendo apenas informações dos endereços dos mesmos. Portanto, concomitantemente à elaboração da planilha, foi realizada a plotagem manual de todos os poços, em seus respectivos endereços, em carta base dotada de malha urbana, viária, hidrografia e linhas de altimetria, na escala 1:20.000. Com a correta plotagem de cada ponto no mapa, foi possível então obter as respectivas coordenadas em UTM, através de cuidadosa projeção cartesiana. Posteriormente, foi empreendida exaustiva checagem das localizações em campo.

A distribuição dos poços na área estudada não é regular, havendo concentração nas áreas centrais da capital curitibana e em outros centros urbanizados dos demais municípios que compõem a Região Metropolitana de Curitiba, em detrimento de zonas pouco urbanizadas ou rurais. Sendo assim, houve necessidade de se pesquisar qual o melhor ajuste e consequente método de interpolação para a adequada modelagem geoestatística dos dados.

As áreas com pouca ou nenhuma amostragem são regiões de maiores incertezas; porém, a geoestatística baseia-se em modelos probabilísticos que levam em conta essas incertezas, extrapolando e interpolando os valores conhecidos para as áreas onde são desconhecidos. A fidelidade dos resultados dependerá, muito, da qualidade das informações numéricas trabalhadas e do prévio conhecimento da contextualização do objeto estudado.

A geoestatística parte da premissa de que dois dados numéricos possuem valores cada vez mais semelhantes quanto mais os dois estiverem próximos no espaço (inferência Bayesiana). Por consequência, quanto mais distantes estiverem, um do outro, dependendo das características ambientais, maior será a discrepância, sendo que a partir de certa distância os valores podem ser totalmente discrepantes, ou seja, aleatórios. Nesse sentido, a geoestatística propõe, através de um conjunto de ferramentas apropriadas, trabalhar a aparente aleatoriedade dos dados (variáveis regionalizadas), tornando possível uma estruturação espacial. É estabelecida, desse modo, uma função para a correlação espacial (variograma). Esta função representa a base da estimativa da variabilidade espacial em geoestatística.

Em outras palavras, "o variograma é a ferramenta básica que permite descrever quantitativamente a variação no espaço de um fenômeno regionalizado" (HUIJBREGTS, 1975).

Supondo que $\mathrm{Z}(\mathrm{x})$ represente o valor de uma variável para um local $\mathrm{x}$, onde $\mathrm{x}$ é o vetor $(\mathrm{x}, \mathrm{y})$; e que $\mathrm{Z}(\mathrm{x}+\mathrm{h})$ represente $o$ valor da mesma variável para uma determinada distância h, em qualquer direção. $\mathrm{O}$ variograma resume a continuidade espacial para todos os pareamentos (comparação de dois valores) e para todos os $\mathrm{h}$ significativos.

A dependência espacial é analisada, segundo Isaaks \& Srivastava (1989), pela função:

$$
\gamma(\mathrm{h})=\frac{1}{2 \mathrm{~N}(\mathrm{~h})} \sum_{\mathrm{i}=1}^{\mathrm{N}(\mathrm{h})}\left[\mathrm{Z}\left(\mathrm{x}_{\mathrm{i}}\right)-\mathrm{Z}\left(\mathrm{x}_{\mathrm{i}}+\mathrm{h}\right)\right]^{2}
$$

onde:

$\gamma$ (h) é o valor do semivariograma estimado para a distância h;

x é a medida de posição;

$\mathbf{h}$ é a distância entre medições.

O modelo de semivariograma representa a estrutura de correlação espacial que será usada nos procedimentos de krigagem e simulação. 
A Krigagem constitui-se num excelente método de interpolação de dados, pois, faz uma descrição mais acurada da estrutura espacial dos dados e produz valiosa informação sobre a distribuição da estimativa do erro.

Rossi et al. (1994, apud ZIMBACK, 2003), destaca uma característica fundamental que distingue a Krigagem dos outros métodos de interpolação: enquanto os métodos tradicionais usam distâncias Euclidianas para avaliar as amostras, a Krigagem tem a vantagem de usar a distância e a geometria (relação de anisotropia) entre as amostras. Por outro lado, diferente dos demais métodos, a Krigagem leva em conta a minimização da variância do erro esperado, por meio de um modelo empírico da continuidade espacial existente ou do grau de dependência espacial com a distância ou direção, isto é, através do variograma.

A Krigagem Ordinária, que é a variação mais utilizada da Krigagem simples, é descrita como sendo o valor inter-

polado $\hat{\mathrm{Z}}\left(\mathrm{x}_{0}\right)$ de uma variável regionalizada $\mathrm{Z}$, num local $\mathrm{x}_{\mathrm{o}}$; podendo ser determinada por:

$$
\hat{Z}\left(x_{0}\right)=\sum_{i=1}^{n}\left[\lambda_{i} \cdot Z\left(x_{i}\right)\right]
$$

onde: trado;

$\hat{\mathrm{Z}}\left(\mathrm{x}_{0}\right)$ é o valor estimado para o local $\mathrm{x}_{\mathrm{o}}$ não amos-

$\mathrm{Z}(\mathrm{Xi})$ é o valor obtido por amostragem no campo; n é o número de amostras vizinhas;

$\lambda_{\mathrm{i}}$ são pesos aplicados em cada $\mathrm{Z}\left(\mathrm{Xi}_{\mathrm{i}}\right)$, ou seja, ponderadores obtidos pela resolução do sistema linear de equações.

O sistema de Krigagem Ordinária tem solução única se o modelo de variograma for válido. A Krigagem, além de ser um estimador não tendencioso, é um interpolador exato, isto é, se o ponto a ser estimado coincidir com um dos pontos amostrados, o valor estimado deverá ser igual ao valor amostrado (YAMAMOTO, 2000).

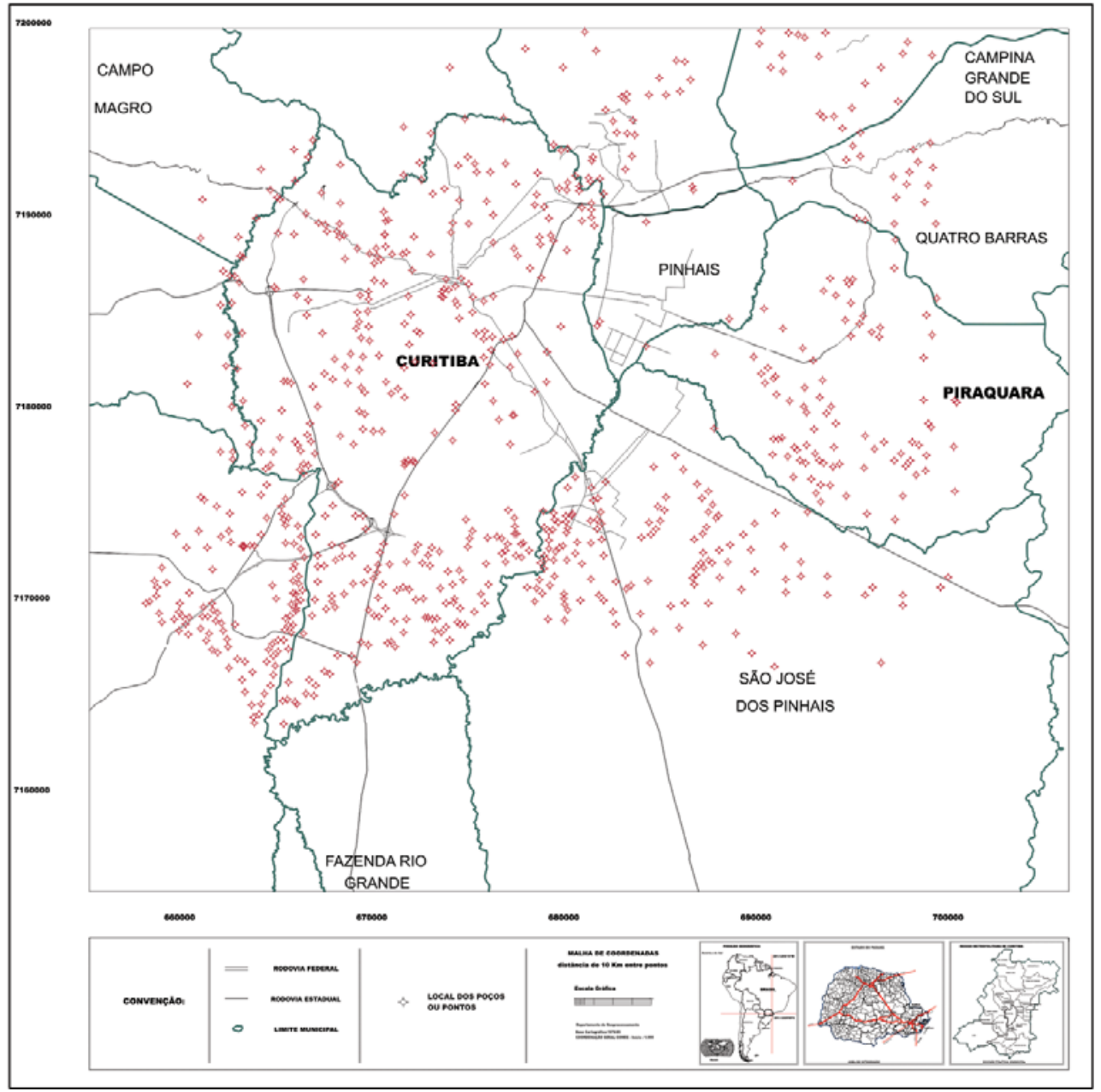

Figura 3 - Mapa de localização dos poços e pontos de controle. Carta base modificada e adaptada de COMEC (2002). Coordenadas em UTM, longitude $E$ e latitude N. Fonte: Archela (2004) 


\section{Apresentação e discussão dos resultados}

A construção, por aproximação, dos mapas da topografia atual e a topografia do embasamento cristalino, sotoposto aos sedimentos da Bacia de Curitiba, foi desenvolvida a partir das informações disponíveis em 276 poços tubulares profundos, cujas localizações são mostradas na figura 3. Sendo que para a construção do mapa da topografia atual foram utilizados os dados das cotas da "boca do poço" para todos os poços e, também, de pontos auxiliares, previamente retirados de cartas topográficas em escala 1:20.000.

A análise estatística descritiva dos dados revela que as cotas altimétricas, para a topografia atual, apresentam média de 905 metros, com uma dispersão média em torno desse valor de 25,57 metros e coeficiente de variação de $2,82 \%$; o que caracteriza uma baixa variabilidade dos dados amostrados. O menor valor (839 metros) e o maior valor (1009 metros) observados reforçam a característica de baixa variabilidade das observações e também mostram que, provavelmente, não há valores discrepantes que poderiam ser atribuídos a erros de determinação, digitação ou amostragem (figura 4).

O histograma mostra uma tendência dos dados à assimetria positiva e este fato também pode ser verificado por meio dos coeficientes de assimetria e curtose associados aos seus respectivos erros padrão que são, respectivamente: 1,88 $\pm 0,09$ e $4,01 \pm 0,18$ (figuras 4 e $\mathbf{5}$ ).

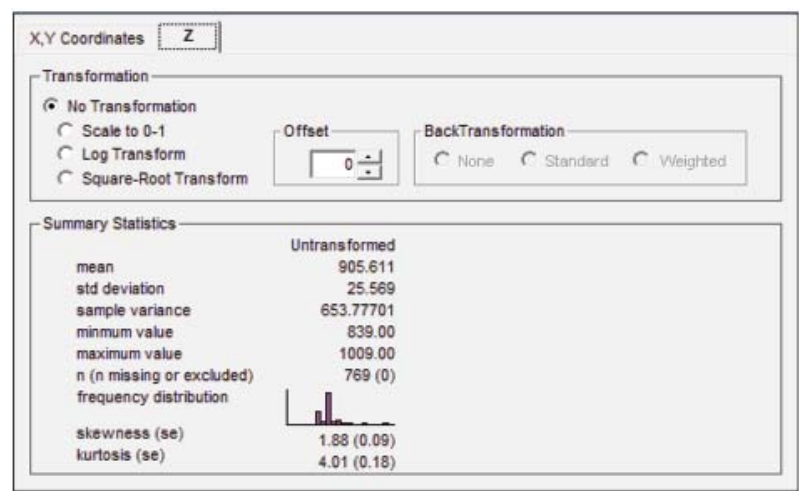

Figura 4-Estatísticas descritivas.

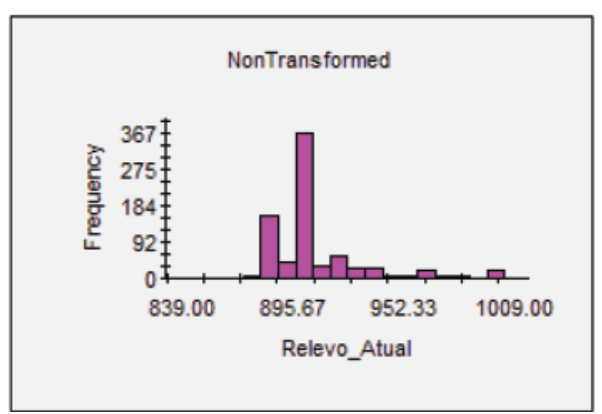

Figura 5-Histograma.
Para a análise do variograma isotrópico, o ângulo de tolerância adotado foi de $90^{\circ}$, pois neste caso os variogramas para as diferentes direções serão iguais (figura 6). Conforme observado na figura 7 , o modelo ajustado aos dados da topografia atual é o esférico, com um valor do efeito pepita de 188 e patamar de 1186,9 . O alcance encontrado para a cota altimétrica da "boca do poço" é de 56.040 metros; ou seja, num raio de até $56 \mathrm{~km}$ os dados estão correlacionados espacialmente. Apesar da soma de quadrados do erro ser de 42.728, relativamente grande, o valor de $r^{2}$ é de $92 \%$; mostrando, assim, que o modelo ajustado ao variograma experimental é adequado. A relação entre "C" e o patamar; ou seja, o índice de dependência espacial é de $84 \%$; o que representa moderada dependência espacial.

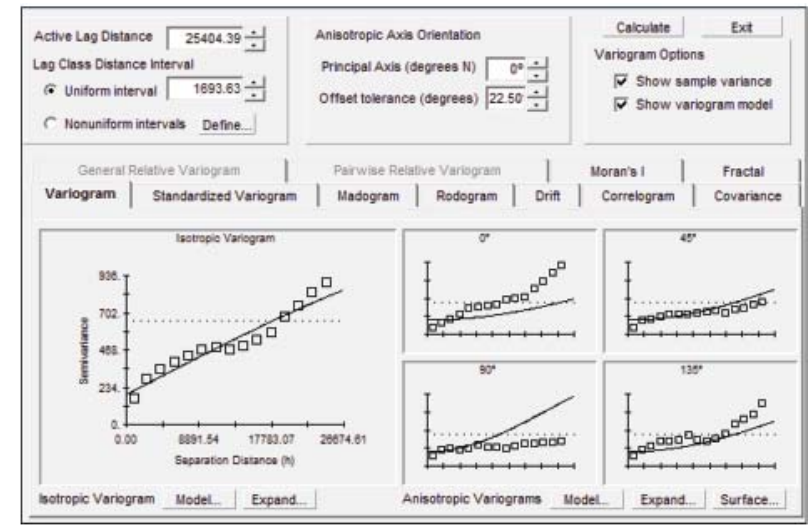

Figura 6-Análise de correlação.

\begin{tabular}{|c|c|c|c|c|}
\hline \multirow{2}{*}{\multicolumn{2}{|c|}{$\begin{array}{l}\text { Variogram } \\
\text { Model Type }\end{array}$}} & \multirow{2}{*}{$\begin{array}{l}\text { Nugget } \\
\text { Variance (Co) }\end{array}$} & \multicolumn{2}{|c|}{ Structural Variance } \\
\hline & & & \multirow{2}{*}{$\begin{array}{l}\text { Sill }\left(\mathrm{CO}_{0}+\mathrm{C}\right) \\
1186.90000 \mathrm{C}\end{array}$} & \multirow{2}{*}{$\begin{array}{l}\text { Range (A) } \\
56040.0000\end{array}$} \\
\hline Spherical & - & 188.000000 & & \\
\hline & & $-\sqrt{. \cdot 1}$ & 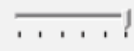 & m. \\
\hline \multicolumn{3}{|l|}{ - This Fit - } & \multicolumn{2}{|c|}{ AutoFit- } \\
\hline \multicolumn{2}{|c|}{ Residual SS: } & 42728. & \multicolumn{2}{|c|}{42728.} \\
\hline \multicolumn{2}{|c|}{$\begin{array}{l}\text { I2: } \\
\text { Proportion }(\mathrm{C} / \mathrm{CO}+\mathrm{Cl}) \text { : }\end{array}$} & 0.923 & \multicolumn{2}{|c|}{0.923} \\
\hline \multirow{2}{*}{\multicolumn{2}{|c|}{$\begin{array}{l}\text { Proportion }(\mathrm{C} /[\mathrm{Co}+\mathrm{C}]) \text { : } \\
\text { Model: }\end{array}$}} & ): 0.842 & \multirow{2}{*}{\multicolumn{2}{|c|}{$\begin{array}{l}0.842 \\
\text { Spherical }\end{array}$}} \\
\hline & & Spherical & & \\
\hline
\end{tabular}

Figura 7 - Modelo ajustado.

O variograma experimental e o modelo ajustado podem ser verificados na figura 8. A interpolação dos dados foi feita por krigagem pontual. O coeficiente de regressão apresenta o ajuste da equação de regressão linear entre os valores reais e os valores estimados por interpolação. De acordo com o resultado da validação cruzada (figura 9), a interpolação por krigagem está estimando bem os dados de relevo atual. 


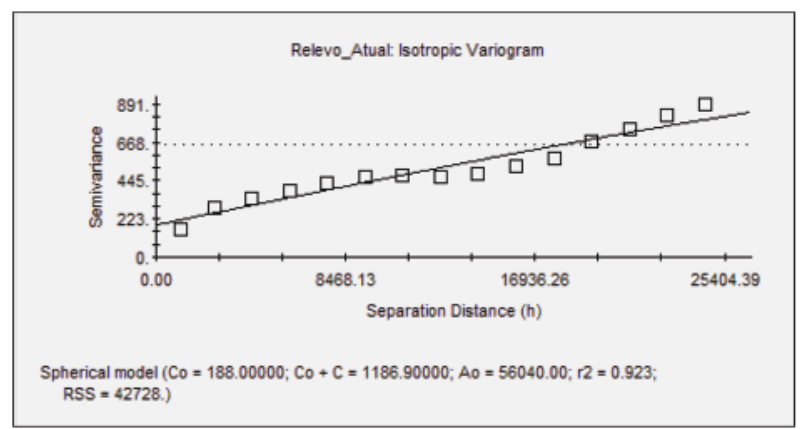

Figura 8-Variograma experimental e modelo ajustado.

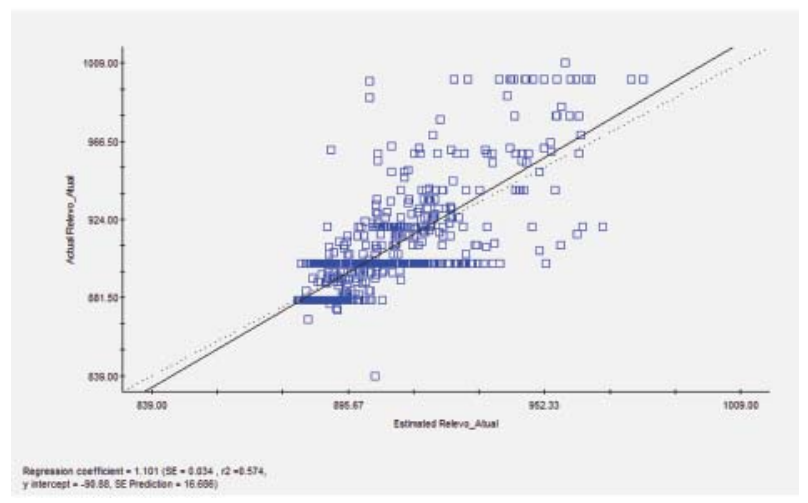

Figura 9 - Validação cruzada para a Krigagem.

O mapa de tendência topográfica para o relevo atual em 2D (figura 10), revelou-se muito bem ajustado quando comparado às cartas altimétricas obtidas por cartografia topografia tradicional. Isso nos permite confiar na fidelidade do mapa da topografia pretérita (embasamento sotoposto aos sedimentos), gerado a partir deste mesmo processo.

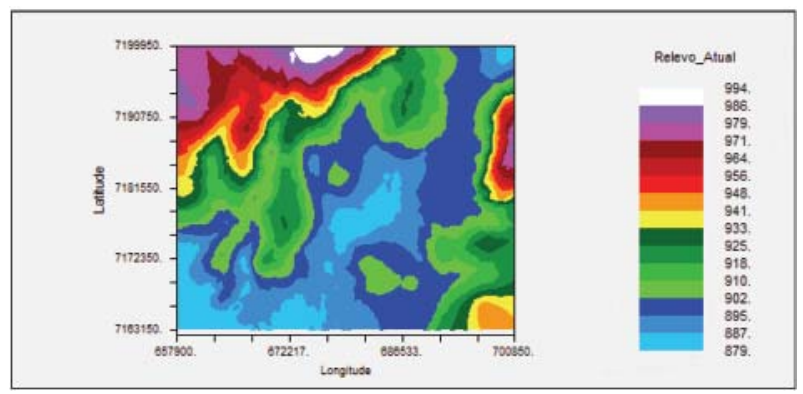

Figura 10-Mapa de tendência topográfica para o relevo atual em $2 D$.

O modelo digital de terreno (MDT ou 3D), gerado a partir dos mesmos dados da figura anterior, facilita a visualização do relevo da área estudada (figura 11). Os principais rios que cortam a região encaixam-se nos vales, nitidamente destacados na topografia. O vale mais amplo foi esculpido pela principal drenagem da área, que é o rio Iguaçu. É per- ceptível uma amplitude de vale mais acentuada a nordeste, migrando para o centro leste, até o sul da área focalizada, onde este muda de rumo e de amplitude. Em outras palavras, o rio Iguaçu passa de um regime meandrante estagnado com amplas planícies de inundação, para um regime mais dinâmico e menos estagnado a partir da região sudoeste, nas imediações da recepção dos afluentes Barigüi e Passa-Una.

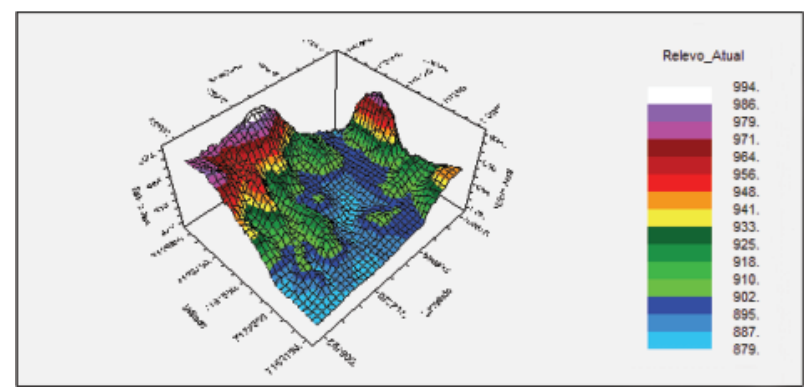

Figura 11-Modelo digital de terreno (MDT ou 3D) para o relevo atual.

A análise estatística descritiva dos dados de cotas altimétricas do paleo-relevo do embasamento enterrado (obtidos pelo resultado da subtração do valor da cota da "boca do poço" menos a espessura de sedimentos em cada poço) apresentou media de 900 metros, com uma dispersão média, em torno desse valor, de 27,73 metros e coeficiente de variação de 3,08\%; o que caracteriza baixa variabilidade dos dados amostrados. O menor valor observado (825 metros) e o maior valor observado (1.009 metros) reforçam a ideia de baixa variabilidade das observações e também mostram que, provavelmente, não há valores discrepantes que poderiam ser atribuídos a erros de determinação, digitação ou amostragem (figura 12).

O histograma mostra uma tendência dos dados à assimetria positiva, e este fato também pode ser verificado por meio dos coeficientes de assimetria e curtose associados aos seus respectivos erros padrão que são, respectivamente: 1,52 $\pm 0,09$ e 3,93 $\pm 0,18$ (figuras 12 e $\mathbf{1 3}$ ).

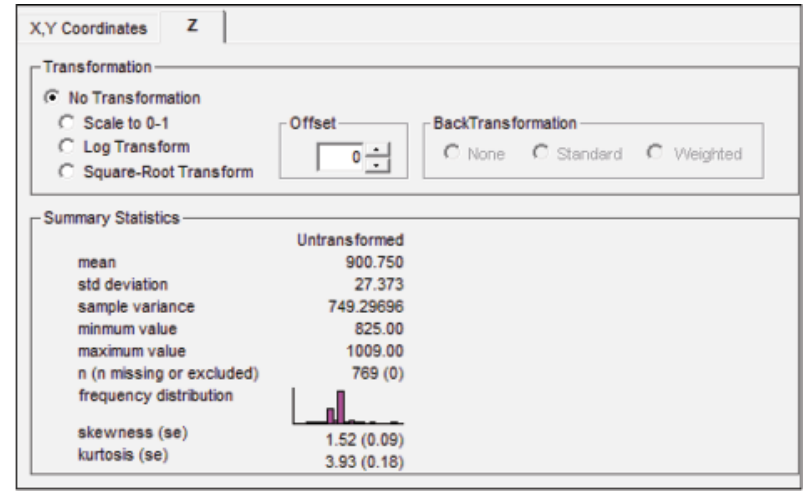

Figura 12 - Estatísticas descritivas. 


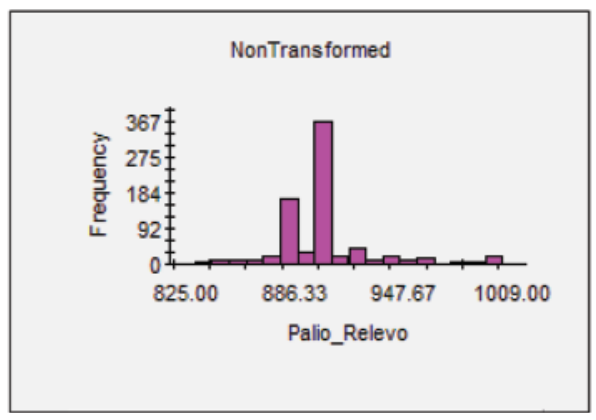

Figura 13 - Histograma.

Para a análise do variograma isotrópico, o ângulo de tolerância adotado foi de $90^{\circ}$, pois neste caso os variogramas para as diferentes direções serão iguais (figura 14). Conforme observado na figura 15, o modelo ajustado aos dados da topografia do paleo-relevo é o exponencial, com um valor de efeito pepita de 140 e patamar de 1.031,50. $\mathrm{O}$ alcance encontrado para as cotas altimétricas do paleorelevo é de 42.780 metros; ou seja, num raio de até $42 \mathrm{~km}$ os dados estão correlacionados espacialmente. Apesar da soma de quadrados do erro ser de 31.967, relativamente grande, o valor de $\mathrm{r}^{2}$ é de $95 \%$; mostrando, assim, que o modelo ajustado ao variograma experimental é adequado. A relação entre "C" e o patamar; ou seja, o índice de dependência espacial, é de $86 \%$; apresentando moderada dependência espacial.

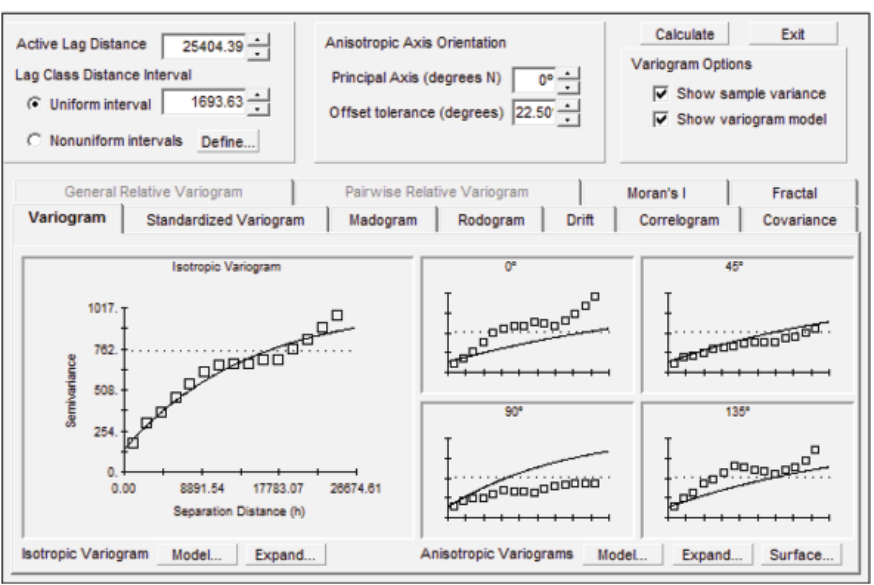

Figura 14 - Análise de correlação.

O variograma experimental e o modelo ajustado podem ser vistos na figura 16. A interpolação dos dados foi feita por krigagem pontual. O coeficiente de regressão apresenta o ajuste da equação de regressão linear entre os valores reais e os valores estimados por interpolação. De acordo com o resultado da validação cruzada (figura 17), a interpolação por krigagem está estimando bem os dados de cotas do paleorelevo enterrado.

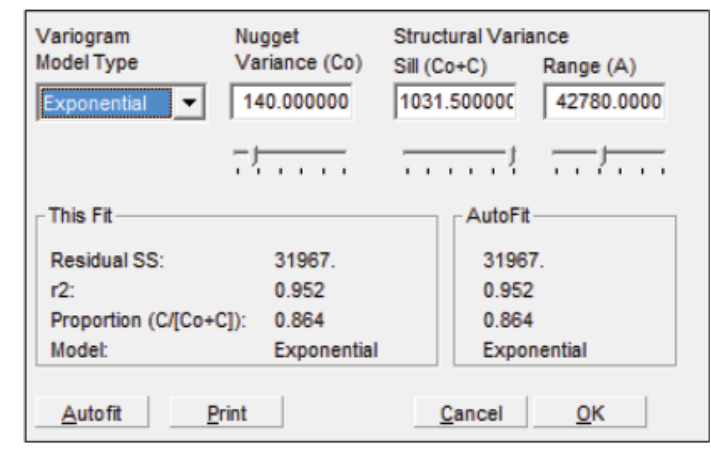

Figura 15 - Modelo ajustado.

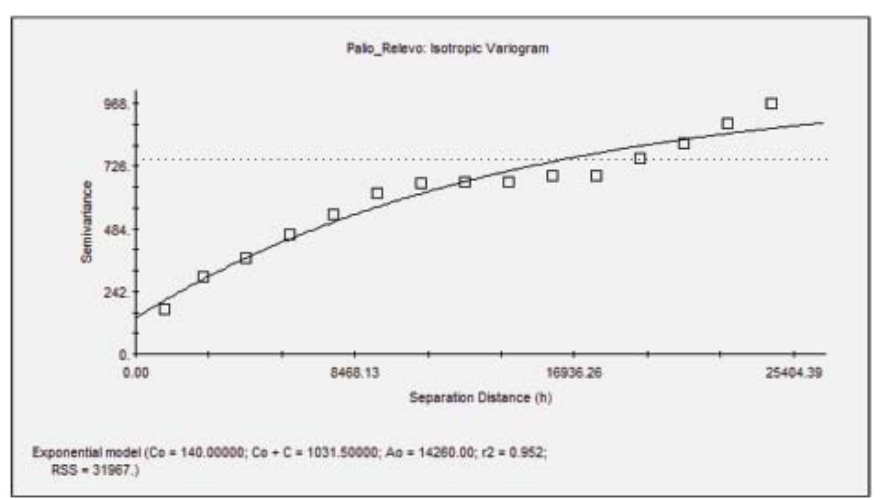

Figura 16 - Variograma experimental e modelo ajustado.

$6 p t$

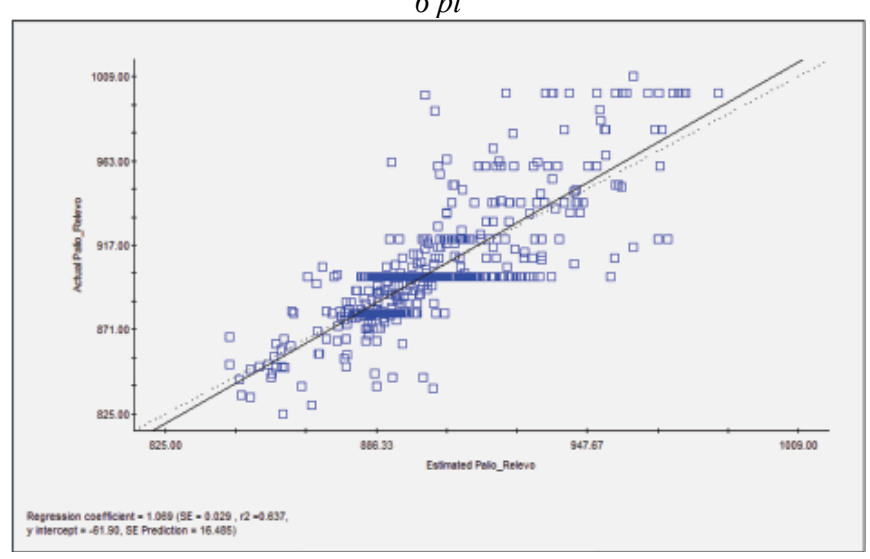

Figura 17 - Validação cruzada para a Krigagem.

O mapa de tendência topográfica para o Embasamento Cristalino enterrado, em 2D (figura 18), possibilitou a visualização dos depocentros de sedimentação. A análise do mapa revela um depocentro principal na região central da bacia, seguido por outros depocentros, alinhados segundo a direção NNE-SSW. Verifica-se, também, que este alinhamento dos depocentros ocorre num vale primordial, geomorfologicamente idêntico ao atual vale fluvial do rio Iguaçu, ocupando uma calha nitidamente tectônica; o que corrobora e reforça a ideia vigente de gênese tectônica para o embaciamento sedimentar. 


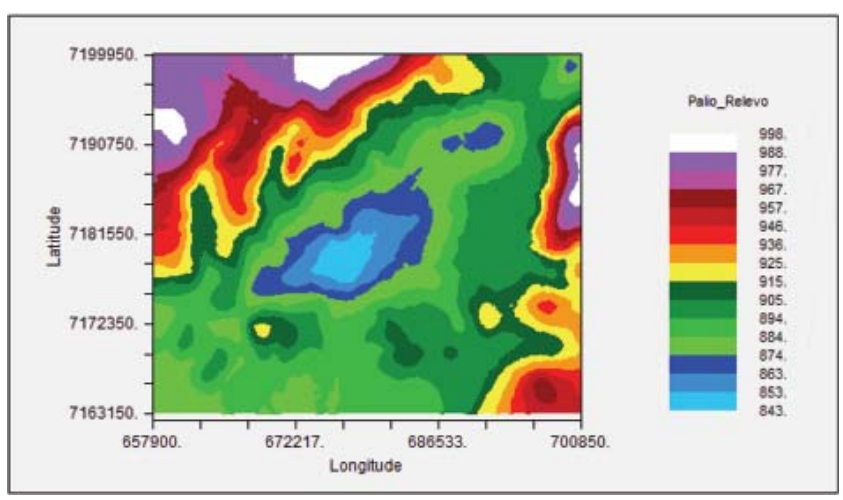

Figura 18 - Mapa de tendência topográfica para o paleo-relevo enterrado em $2 D$.

O modelo digital de terreno (MDT ou 3D), gerado a partir dos mesmos dados da figura anterior, facilita a visualização do relevo do embasamento enterrado (figura 19). Os principais rios que cortam a região encaixam-se nos vales, nitidamente destacados na topografia. O vale mais amplo foi esculpido pela principal drenagem da área, que é o rio Iguaçu. É perceptível uma amplitude de vale mais acentuada a nordeste, migrando para o centro leste, até o sul da área focalizada, onde este muda de rumo e de amplitude. Em outras palavras, o rio Iguaçu passa de um regime meandrante estagnado com amplas planícies de inundação, para um regime mais dinâmico e menos estagnado a partir da região sudoeste, nas imediações da recepção dos afluentes Barigüi e Passa-Una.

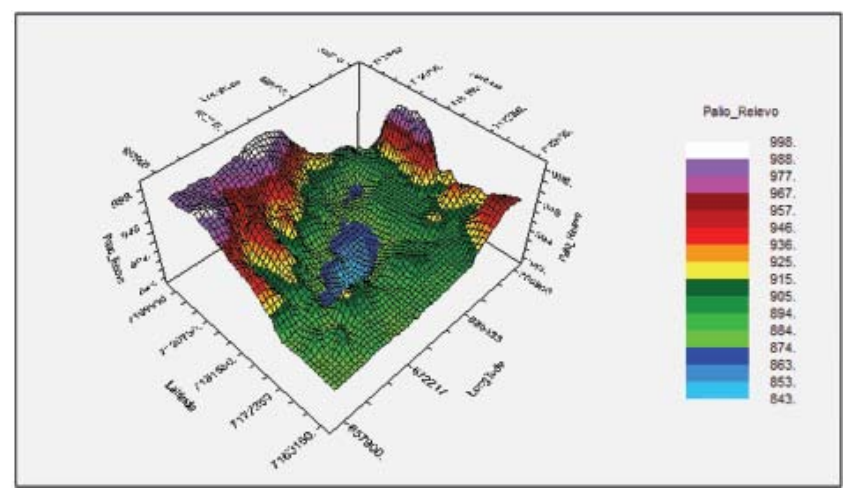

Figura 19 - Modelo digital de terreno (MDT ou 3D) para o paleorelevo enterrado.

A maior depressão do embasamento atinge a cota 825 metros, sendo que a cota média está em torno dos 900 metros. O relevo atual, como elemento comparativo, possui altitude média ao redor de 905 metros; chegando a 839 metros como cota mínima topográfica, e atingindo 1009 metros de altitude máxima, dentro da área pesquisada. Estes dados revelam a pequena espessura de depósitos sedimentares da Bacia de Curitiba (pouco mais de 80 metros) e, também, a probabili- dade estatística de ocorrência de "janelas" do embasamento cristalino em meio à exposição areal dos sedimentos; fato este, corriqueiramente observável em campo. Outra importante constatação é o padrão estrutural observado no relevo do embasamento que, a exemplo daquele observado na topografia atual, reflete os mesmos alinhamentos estruturais.

Ao se observar o mapa geológico da figura 2, e confrontando-o com os dois mapas obtidos neste trabalho (figuras 10, 11, 18 e 19), verifica-se que as atuais drenagens encaixam-se em importantes alinhamentos estruturais do Embasamento Cristalino, num imbrincamento de grandes blocos cujas porções mais deprimidas encontram-se nas porções centrais da Bacia Sedimentar de Curitiba; sugerindo que as atuais principais redes de drenagens não diferem, em essência, daquelas contemporâneas à gênese da bacia. Essa conformação geomorfológica também explica a mudança de regime hídrico observada para o rio Iguaçu, onde o basculamento de blocos tectônicos propiciou, já nos primórdios genéticos da estruturação da bacia, centros de represamentos mais profundos para as águas de drenagens que provinham dos altos estruturais tectônicos, hoje parcialmente expostos no entorno.

\section{Conclusões}

Os resultados apresentados permitem enumerar as seguintes conclusões: 1) o mapa do relevo atual, obtido por aproximação geoestatística pelo método da krigagem a partir de dados pontuais aleatórios, mostrou-se fidedigno quando comparado com cartas topográficas obtidas por topografia convencional; 2) as feições geomorfológicas do paleo-relevo enterrado apresentam características muito semelhantes daquelas observadas no relevo atual; 3) o "trend" estrutural do embasamento sotoposto aos sedimentos, com evidentes linhas de estruturação de blocos na direção NNE-SSW, reforçam a tese de uma gênese tectônica para a Bacia de Curitiba, associando-a as demais bacias tafrogênicas que compõem o "Rift Continental do Sudeste do Brasil"; e 4) As principais drenagens pretéritas assemelham-se muito às atuais, não só nas distribuições geográficas, mas principalmente na função de agentes de transporte e retrabalhamento dos sedimentos aluviais, ocupando os depocentros alinhados do paleo-relevo.

\section{Referências Bibliográficas}

AB'SABER, A. N.; BIGARELLA, J. J. Superfícies aplainadas no Primeiro Planalto do Paraná. Boletim Paranaense de Geografia. Curitiba, n. 4/5, p. 116-125, 1961.

ALMEIDA, F. F. M.; HASUI, Y. (org.) O Pré-Cambriano do Brasil. São Paulo: EDUSP, 1984.

ARCHELA, E. Faciologia e ambientes de sedimentação da Bacia de Curitiba. São Paulo: IGUSP, 1990. 167 p. (relatório científico FAPESP). 
ARCHELA, E. O sistema de "rifts" da Serra do Mar e as bacias sedimentares associadas. São Paulo: IGUSP, 1989. 42 p. (mimeo).

ARCHELA, E. Disponibilidade hídrica subterrânea na área de abrangência da Bacia Sedimentar de Curitiba-PR: uma contribuição da faciologia sedimentar para a caracterização do Aqüífero Guabirotuba, corroborada por análises estatísticas das vazões. 2004. 270 p. Dissertação (Mestrado em Meio Ambiente) - Universidade Estadual de Londrina. Londrina.

ARCHELA, E. Relações entre a faciologia e a disponibilidade hídrica subterrânea na Bacia Sedimentar de Curitiba. In: SIMPÓSIO DO CRETÁCEO DO BRASIL, 7 / SIMPÓSIO DO TERCIÁRIO DO BRASIL, 1, 2006, Serra Negra. Boletim de Resumos... Rio Claro: UNESP - Universidade Estadual Paulista "Júlio de Mesquita Filho", Instituto de Geociências e Ciências Exatas, 2006. v. 1, p. 13-13.

ARCHELA, E; COIMBRA, A. M. Faciologia e ambientes de sedimentação da Bacia de Curitiba. In: GEOPAR I - SIMPÓSIO AMBIENTES GEOLÓGICOS DOS RECURSOS NATURAIS DO PARANÁ, 2006, Curitiba. Boletim de Resumos... Curitiba: Sociedade Brasileira de Geologia - Núcleo Paraná, 2006. v. 01. p. 47-48.

ARCHELA, E.; YAMAMOTO, J. K. Avaliação hídrica subterrânea na Região Metropolitana de Curitiba-PR. In: SEMINÁRIO NACIONAL SOBRE REGENERAÇÃO AMBIENTAL DE CIDADES - ÁGUAS URBANAS II, 2, 2007, Londrina. Anais... Londrina: UEL - Universidade Estadual de Londrina, Centro de Ciências Exatas, Departamento de Geociências, 2007. p. 506-525. (CD-ROM).

ARCHELA, E.; YAMAMOTO, J. K. Avaliação hídrica subterrânea do Aqüífero Cristalino na Região Metropolitana de Curitiba-PR. In: Águas Urbanas: memória, gestão, riscos e regeneração. Londrina: EDUEL, 2008c.

ARCHELA, E.; YAMAMOTO, J. K. Identificação e tendência na distribuição das fácies sedimentares presentes na Bacia de Curitiba-PR. In: CONGRESSO BRASILEIRO DE GEOLOGIA, 44, 2008, Curitiba. Anais... Curitiba: Sociedade Brasileira de Geologia, 2008a.

ARCHELA, E.; YAMAMOTO, J. K. Modelagem do paleorelevo do embasamento da Bacia Sedimentar de Curitiba-PR. In: CONGRESSO BRASILEIRO DE GEOLOGIA, 44, 2008, Curitiba. Anais... Curitiba: Sociedade Brasileira de Geologia, 2008b.

COMEC - Coordenação da Região Metropolitana de Curitiba. Mapa Digital da Região Metropolitana de Curitiba. Curitiba 2002. (CD-ROM).
HUIJBREGTS, C. J. Regionalized variables and quantitative analysis of spatial data. In: DAVIS, J. C. \& MCCULLAGH, M. J. (eds.) Display and analysis of spatial data. New York: John Wiley, 1975. p. 38-53.

ISAAKS, E. H.; SRIVASTAVA, R. M. An Introduction to Applied Geostatistic. New York: Oxford University Press, 1989. $560 \mathrm{p}$.

RICCOMINI, C.; COIMBRA, A. M.; SANT'ANNA, L. G.; BRANDT NETO, M.; VALARELLI, J. V. Argilominerais do paleolago Tremembé e sistemas deposicionais relacionados (Paleógeno, Rift Continental do Sudeste do Brasil). Revista Brasileira de Geociências, v. 26, n. 3, p. 167-180, 1996.

RICCOMINI, C.; SANT'ANNA, L. G.; FERRARI, A. L. Evolução geológica do Rift Continental do Sudeste do Brasil. In: Mantesso-Neto , V.; Bartorelli, A.; Dal Ré Carneiro, C.; Brito Neves, B. (org.) Geologia do continente sul-americano: evolução da obra de Fernando Flávio Marques de Almeida. São Paulo: Beca, 2004. p. 383-405.

RICCOMINI, C. O Rift Continental do Sudeste do Brasil. 1989. 256 p. Tese (Doutorado em Geociências) - Universidade de São Paulo. São Paulo.

SALAMUNI, E.; EBERT, H. D.; BORGES, M. S.; HASUI, Y.; COSTA, J. B. S.; SALAMUNI, R. Tectonics and sedimentation of the Curitiba Basin. Journal of South American Earth Sciences, v. 15, n. 8, p. 901-910, 2003.

SALAMUNI, E. Tectônica da Bacia Sedimentar de Curitiba (PR). 1998. 215 p. Tese (Doutorado em Geologia Regional) Universidade Estadual Júlio de Mesquita Filho. Rio Claro.

SALVADOR, E. D. Análise neotectônica da região do vale do rio Paraíba do Sul compreendida entre Cruzeiro (SP) e Itatiaia (RJ). 1994. Dissertação (Mestrado em Geologia Sedimentar) - Universidade de São Paulo. São Paulo.

SALVI, R. F.; ARCHELA, E.; ARCHELA, R. S. Breve descrição da formação do território paranaense. In: Fresca, T. M; SALVI, R. F.; ARCHELA, R. S (org.) Dimensões do espaço paranaense. Londrina: EDUEL, 2002.

YAMAMOTO, J. K. An alternative measure of the reliability of ordinary kriging estimates. Mathematical Geology, EUA, v. 32 , n. 4, 2000, p. 489-509.

ZIMBACK, C. R. L. Geoestatística. Botucatu: FCA-UNESP, 2003. 25 p. (apostila). 